\title{
Effect of Homocysteine and Homocystine on Platelet and Vascular Arachidonic Acid Metabolism
}

\author{
JANET E. GRAEBER, ${ }^{(18)}$ JEFFREY H. SLOTT, RODNEY E. ULANE, JOSEPH D. SCHULMAN, AND \\ MARIE J. STUART \\ Neonatal and Pediatric Medicine Branch, National Institute of Child Health and Human Development, National \\ Institutes of Health, Bethesda, Maryland [J.E.G., R.E.U., J.D.S.] and Department of Pediatrics, SUNY, Upstate \\ Medical Center, Syracuse, New York [J.H.S., M.J.S.], USA
}

\begin{abstract}
Summary
Normal hemostasis depends in part on the balance achieved between proaggregatory and prothrombotic platelet thromboxane $A_{2}$, measured as its stable end-product thromboxane $\mathbf{B}_{2}\left(\mathrm{TXB}_{2}\right)$, and vascular prostacyclin (PGI $)$, which inhibits platelet aggregation and is antithrombotic. Cystathionine- $\beta$-synthase deficiency is characterized by a high frequency of thromboembolic disease. We therefore studied, in vitro, the effects of homocysteine and related compounds on platelet $\mathrm{TXB}_{2}$ and vascular $\mathrm{PGI}_{2}$ formation.

In paired samples of platelet rich plasma, which had been preincubated with $\mathrm{L}$-homocystine $(1 \mathrm{mM})$, mean production of the two platelet cyclooxygenase products, $\mathrm{TXB}_{2}$ and 12-hydroxy-5, 8,10-heptadecatrienoic acid increased significantly from control levels $\left[13.6 \% \pm 1.9\right.$ to $19.8 \% \pm 2.1(P<0.02) \mathrm{TXB}_{2}$ and $29.8 \% \pm$ 4.2 to $39.4 \% \pm 4.1(P<0.01) \mathrm{HHT}$. In the presence of $\mathrm{D}, \mathrm{L}-$ homocysteine (1 mM), mean platelet $\mathrm{TXB}_{2}$ and 12-hydroxy-5,8,10heptadecatrienoic acid production was also significantly increased $\left[12.7 \% \pm 1.5\right.$ to $16.9 \% \pm 1.5(P<0.01) \mathrm{TXB}_{2}$ and $27 \% \pm 4$ to $31 \%$ $\pm 4.1(P<0.02)$ HHT]. Cystine, cysteine, or methionine $(1 \mathrm{mM})$ did not have similar effects in this test system. Homocysteine and homocystine were without effect on the synthesis of vascular $\mathbf{P G I}_{2}$ by umbilical artery segments [control, $0.22 \pm 0.03$ to $0.21 \pm 0.03$ $\mathrm{ng} / \mathrm{mg}$ with D,L-homocysteine and $0.20 \pm 0.04$ control to $0.19 \pm$ $0.04 \mathrm{ng} / \mathrm{mg}$ with $\mathrm{D}, \mathrm{L}-$-homocystine]. A homocyst(e)ine-induced increase in platelet thromboxane production in the absence of an increase in vascular prostacyclin, if present in vivo, may contribute to the vascular thromboses characteristic of human homocystinemias (homocystinurias).
\end{abstract}

The homocystinurias occur as a result of genetically determined defects in the metabolism of homocysteine (15). The most common etiology, cystathionine- $\beta$-synthase deficiency, results in a decrease in the rate of conversion of homocysteine to cystathionine and is generally accompanied by hypermethioninemia. Deficiencies in the remethylation of homocysteine to methionine cause homocystinemia accompanied by hypomethioninemia but are much less common. In all these disorders, accumulated homocysteine is oxidized to homocystine, which is found in excessive amounts in blood and urine.

Cystathionine- $\beta$-synthase dificiency is characterized by ectopia lentis, skeletal deformities, central nervous system abnormalities and a high frequency of thromboembolic disease. Atherosclerosis and occlusion of major vessels such as myocardial, cerebral, renal and pulmonary arteries and veins may occur as early as the first decade, often with fatal results (15).

Studies on other disorders with a high incidence of thrombotic complications suggest that normal hemostasis depends in part on the balance achieved between proaggregatory and prothrombotic platelet thromboxane $A_{2}$ and vascular prostacyclin, which inhibits platelet aggregation and is thus antithrombotic (14). We therefore undertook an in vitro study of the effects of homocysteine and related compounds on platelet thromboxane and vascular prostacyclin formation.

\section{MATERIALS AND METHODS}

Evaluation of platelet arachidonic acid metabolism after incubation in vitro with homocystine, homocysteine, cystine, cysteine, or methionine. Blood samples were obtained after informed consent from control subjects using a two-syringe technique and 9 volumes of blood to 1 volume citrate-phosphate-dextrose solution. Plateletrich plasma (PRP) was obtained by centrifugation of the samples at $200 \times g$ for $20 \mathrm{~min}$. PRP from each control was divided into three aliquots. Hank's balanced salt solution (HBSS) was added to one aliquot as a control, whereas $\mathrm{L}$-homocystine or D,L-homocysteine (1 $\mathrm{mM}$ final concentration in HBSS) was added to each of the other two platelet aliquots. All samples were incubated at $37^{\circ} \mathrm{C}$, at $\mathrm{pH} 7.4$ for $45 \mathrm{~min}$. Each patient's platelets served as their own control in order to evaluate the effects of the test compounds. In a second set of experiments, PRP from controls was divided into four aliquots and incubated with HBSS alone, or L-cystine, D,L-cysteine, or L-methionine ( $1 \mathrm{mM}$ in HBSS) as described above.

To assess platelet conversion of $\left[{ }^{14} \mathrm{C}\right]$-arachidonic acid to metabolites by the lipoxygenase and cyclooxygenase enzymes, the platelets were washed (16) after the period of incubation, and resuspended in $\mathrm{HBSS}\left(37^{\circ} \mathrm{C}\right)$ containing $0.5 \mathrm{mM}$ calcium chloride at a concentration of $5 \times 10^{8}$ platelets per $\mathrm{ml}$. $\left[{ }^{14} \mathrm{C}\right]$-Arachidonic acid (specific activity $56.5 \mathrm{mCi} / \mathrm{mM}$ ) made up as a sodium salt in $0.01 \mathrm{M}$ Tris buffer, $\mathrm{pH} 7.4$, was then added to a $1 \mathrm{ml}$ platelet suspension (final concentration of arachidonate per sample was 6 $\mu \mathrm{M})$. Aggregation was monitored in a Payton dual channel aggregometer. After $6 \mathrm{~min}$, the samples were added to extraction vials containing $10 \mathrm{ml}$ of absolute ethanol, then diluted, acidified with $1 \mathrm{~N} \mathrm{HCl}$ to a pH of 3.3 and extracted into diethyl ether. Separation of $\left[{ }^{14} \mathrm{C}\right]$-arachidonic acid from thromboxane $\mathrm{B}_{2}\left(\mathrm{TXB}_{2}\right)$ was performed by thin layer chromatography of the free acids on silica gel $\mathrm{G}$ with diethyl ether:methanol:acetic acid (135:5:3, v/v) as eluting solvent. Thromboxane $\mathrm{B}_{2}\left(\mathrm{TXB}_{2}\right)$ standard (kindly supplied by Dr. John E. Pike, Upjohn Co., Kalamazoo, MI) was also applied to each plate. The plates were then scanned on a thinlayer radiochromatogram scanner (Berthold, Wildbad, W. Germany) and the silica gel corresponding to the $\mathrm{TXB}_{2}$ peak scraped from the glass and counted in a scintillation counter. The remaining arachidonate and metabolites on the silica gel plates were extracted into $2 \mathrm{ml}$ ether, then methylated using diazomethane, and separated on a thin layer chromatogram (silica gel B) using the organic layer of isooctane:water:ethyl acetate $(2: 2: 1)$ as mobile 
phase (5). The thin layer plates were scanned using a Berthold radiochromatogram scanner to determine the location of individual peaks. The thin layer plates were also subjected to autoradiography to improve the definition of 12-hydroxy-5,8, 10-heptadecatrienoic acid (HHT) and 12-hydroxy-5,8,10,14-eicosatetraenoic acid (HETE) as depicted in Figure 1. Areas corresponding to individual peaks were then scraped from the plate and counted in a Beckman liquid scintillation counter.

Statistical evaluation was performed using Student's $t$ test for paired samples.

Evaluation of vascular prostaglandin $I_{2}$ by bioassay after incubation in vitro with homocystine and homocysteine. Umbilical cords were obtained from 8 normal full term vaginal deliveries in which there was no evidence for maternal ingestion of aspirin nor other drugs within two wk of delivery. The umbilical cords were dissected, and the umbilical arteries isolated and immediately cleaned externally in $\mathrm{Ca}^{++}$- and $\mathrm{Mg}^{++}$-free HBSS, pH 7.4, at $4^{\circ} \mathrm{C}$. The arteries were cut into small rings. After weighing, approximately 6 arterial rings ( $\sim 40 \mathrm{mg}$ per tube) were suspended in HBSS (with $0.5 \mathrm{mM} \mathrm{Ca}^{++}$and $\left.\mathrm{Mg}^{++}\right)$or HBSS $\left(0.5 \mathrm{mM} \mathrm{Ca}{ }^{++}\right.$and $\mathrm{Mg}^{++}$) containing $1 \mathrm{mM}$ L-homocystine or D,L-homocysteine, $\mathrm{pH} \mathrm{7.4,} \mathrm{in}$ $1 \mathrm{ml}$ final volumes. Following a 20 -min incubation period, the vessels were washed in $1 \mathrm{ml} \mathrm{HBSS}, \mathrm{pH} 7.4$ at $22^{\circ} \mathrm{C}$ and resuspended in $120 \mu$ liters $\mathrm{HBSS}$, pH 8.4 , for $3 \mathrm{~min}$ at $22^{\circ} \mathrm{C}$. Aliquots (1-120 $\mu$ liters) of the supernatant were then added to control PRP $1 \mathrm{~min}$ before the addition of adenosine diphosphate (ADP) $(3 \mu \mathrm{M}$ final concentration). Prostacyclin activity was evaluated in a Payton dual channel aggregometer as described by Moncada et al. (13). The amount of antiaggregatory activity of both the control and test vascular rings was expressed as $\mathrm{ng}$ of $\mathbf{P G I}_{2}$ per $\mathrm{mg}$ wet weight of tissue by extrapolation from a dose response standard curve obtained concomitantly with authentic $\mathrm{PGI}_{2}$ ( a gift from Dr. John E. Pike, Upjohn Co., Kalamazoo, MI). PGI $_{2}$ activity was further characterizied according to previous criteria (13). The activity was heat labile (lost by boiling for $0.25 \mathrm{~min}$ ), unstable at room temperature $\left(22^{\circ} \mathrm{C}\right.$ for $\left.20 \mathrm{~min}\right)$, and its generation was completely inhibited by 30 -min preincubations with acetylsalicylic acid $(100 \mu \mathrm{M})$ or indomethacin $(5 \mu \mathrm{g} / \mathrm{ml})$. Neutralization of prostacyclin activity was possible with an antiserum (kindly supplied by Dr. B. J. Smith, Philadelphia, PA), which selectively antagonized the activity of authentic $\mathrm{PGI}_{2}$. A total of eight separate bioassay experiments were performed and the results evaluated using the $t$ test for paired samples.

\section{RESULTS}

Effect of test compounds on platelet arachidonic acid metabolism. L-homocystine and D,L-homocysteine had significant effects on platelet arachidonic acid metabolism. Figure 2 depicts the effect of $1 \mathrm{mM}$ homocystine on the metabolism of arachidonic acid through the cyclooxygenase pathway in six paired experiments. A significant increase in both $\mathrm{TXB}_{2}$ and HHT was observed. Mean $\mathrm{TXB}_{2}$ production increased from $13.6 \% \pm 1.9$ (1 S.E.) in control platelets to $19.8 \% \pm 2.1$ in paired samples, which had been preincubated with homocystine $(P<0.02)$. Mean HHT production increased from $29.8 \% \pm 4.3$ to $39.4 \% \pm 4.1(P<0.01)$. Increases in $\mathrm{TXB}_{2}$ and $\mathrm{HHT}$ production ranged from $18-140 \%$ in

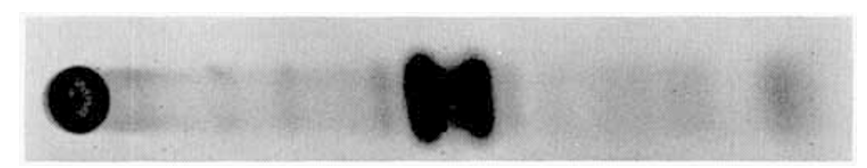

\section{ORIGIN}

\section{HHT HETE}

$A A$

Fig. 1. Autoradiograph of a thin layer chromatogram of a platelet extract showing the separation of HHT (12-hydroxy-5,8,10-heptadecatrienoic acid) and HETE (12-hydroxy-5,8,10,14-eicosatetraenoic acid). each of the six experiments. When the lipoxygenase product HETE was measured in the presence or absence of L-homocystine, no significant mean differences were observed $(38.3 \% \pm 4.2$ and $41 \% \pm 4.9$, respectively)

As shown in Figure 3 similar results were observed in eight paired experiments in the presence of $1 \mathrm{mM} \mathrm{D,L}$-homocysteine. Mean $\mathrm{TXB}_{2}$ production was $12.7 \% \pm 1.5$ in control platelets,


eraged $16.9 \% \pm 1.5(P<0.01)$. $\mathrm{TXB}_{2}$ production increased from $13 \%$ to $85 \%$ over control values in six of eight paired experiments with two remaining relatively unchanged. HHT production was also increased from a mean control value of $27 \% \pm 4$ to $31 \% \pm 4.1$ $(P<0.02)$. HHT production increased from $14 \%$ to $104 \%$ over baseline control values in five of the eight paired experiments with three remaining relatively unchanged. When the lipoxygenase product HETE was measured in the presence or absence of $\mathrm{D}, \mathrm{L}$ homocysteine, mean values were similar $(41.9 \% \pm 3.2$ and $41.5 \%$ \pm 3.6 , respectively).

In contrast to the above results, L-cystine, D,L-cysteine, or Lmethionine had no effect on platelet metabolism through the cyclooxygenase (TXB ${ }_{2}$ and $\mathrm{HHT}$ ) or lipoxygenase (HETE) pathways (Table 1).

$$
\text { (a) } \mathrm{TXB}_{2}
$$

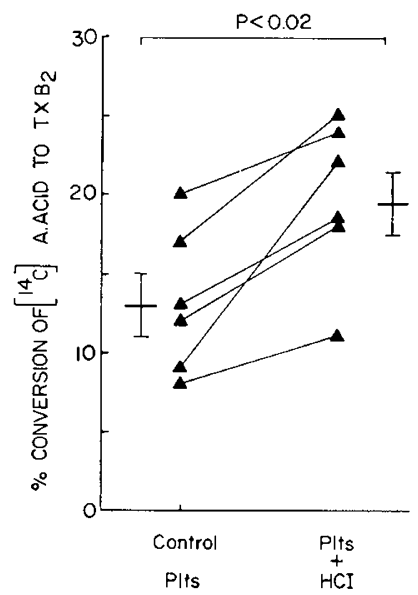

(b) HHT

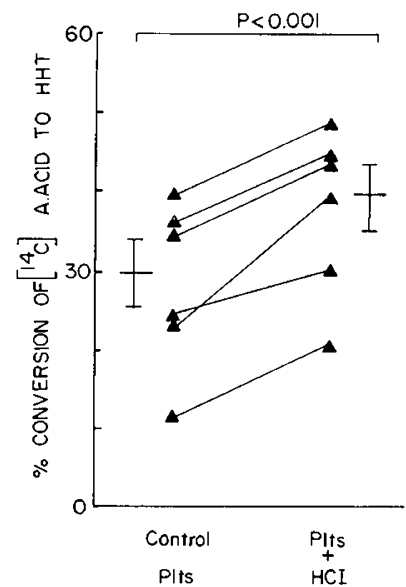

Fig. 2. Effect of $1 \mathrm{mM}$ L-homocystine $(\mathrm{HCI})$ on platelet thromboxane $\mathrm{B}_{2}$ and HHT (12-hydroxy-5,8,10-heptadecatrienoic acid) formation in six paired experiments. Brackets show mean $\pm 1 \mathrm{SE}$. (a) $\mathrm{TXB}_{2}$

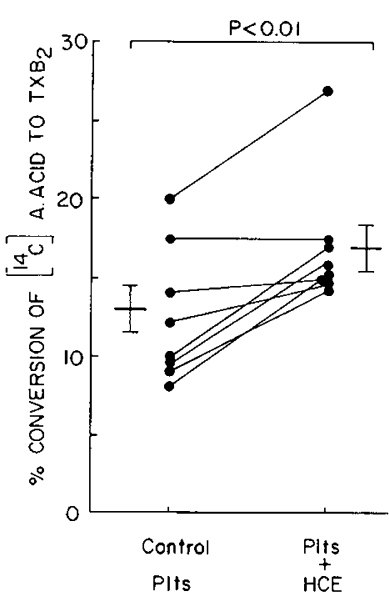

(b) $\mathrm{HHT}$

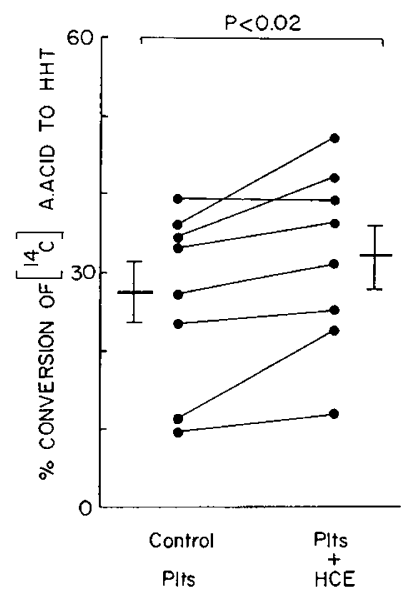

Fig. 3. Effect of $1 \mathrm{mM} \mathrm{D,L-homocysteine} \mathrm{(HCE)} \mathrm{on} \mathrm{platelet} \mathrm{thrombox-}$ ane $B_{2}$ and HHT (12-hydroxy-5,8,10-heptadecatrienoic acid) formation in eight paired experiments. Brackets show mean $\pm 1 \mathrm{SE}$. 
Table 1. Effect of $L$-cystine, D,L-cysteine, and L-methionine on platelet thromboxane $B_{2}, H H T$ and HETE formation in paired experiments

\begin{tabular}{|c|c|c|c|c|c|c|}
\hline \multirow{2}{*}{$\begin{array}{c}\text { Test } \\
\text { Compound }\end{array}$} & \multicolumn{2}{|c|}{$\mathrm{TXB}_{2}$} & \multicolumn{2}{|c|}{ HHT } & \multicolumn{2}{|c|}{ HETE } \\
\hline & Control & Expt. & Control & Expt. & Control & Expt. \\
\hline $\begin{array}{l}\text { L-cystine } \\
\qquad(n=6)\end{array}$ & $12.5 \pm 1.3^{1}$ & $11.2 \pm 1.2$ & $29.2 \pm 2.5$ & $28.1 \pm 2.2$ & $31.9 \pm 2.1$ & $32.8 \pm 1.7$ \\
\hline $\begin{array}{l}\mathrm{D}, \mathrm{L} \text {-cysteine } \\
\quad(n=6)\end{array}$ & $15.6 \pm 2.6$ & $15.0 \pm 2.0$ & $30.3 \pm 2.6$ & $29.9 \pm 2.8$ & $33.3 \pm 2.0$ & $35.3 \pm 2.8$ \\
\hline $\begin{array}{l}\text { L-methionine } \\
\quad(n=7)\end{array}$ & $12.3 \pm 1.3$ & $12.0 \pm 1.6$ & $28.4 \pm 1.4$ & $27.3 \pm 0.9$ & $34.1 \pm 2.3$ & $35.5 \pm 2.4$ \\
\hline
\end{tabular}

${ }^{3}$ Mean $(\%) \pm$ S.E., all paired mean differences are not significant $(P>0.05)$

Effect of homocystine and homocysteine on prostaglandin $I_{2}$ production. As shown in Figure 4, no differences in bioassayable prostacyclin $\left(\mathrm{PGI}_{2}\right)$ production were observed between control vessels and paired samples incubated with either D,L-homocysteine or L-homocystine. Mean $\mathrm{PGI}_{2}$ production was $0.21 \pm 0.03 \mathrm{ng} / \mathrm{mg}$ vascular tissue in the presence of $\mathrm{D}, \mathrm{L}$-homocysteine compared to $0.22 \pm 0.03$ in paired control vessels; and $0.20 \pm 0.04 \mathrm{ng} / \mathrm{mg}$ in control vessels paired to those preincubated with D,L-homocystine $(0.19 \pm 0.04)$.

\section{DISCUSSION}

Vascular occlusive lesions may lead to serious complications in patients with homocystinuria (15). Blood vessel alterations are similar to those of classic atherosclerosis, and are characterized by intimal thickening, medial disorganization and fibrosis with loss of elastic tissue, hyperplasia of smooth muscle cells and mural or occlusive thrombi (11). The precise etiology of these lesions is unknown. Our in vitro data suggest that in the presence of $1 \mathrm{mM}$ homocystine or homocysteine, abnormalities in platelet arachidonic acid metabolism expected to favor thrombosis do occur.

In the platelet, arachidonic acid is liberated from cell membrane phospholipids after stimulation. Released arachidonic acid may then be converted by either the lipoxygenase or the cyclooxygenase pathway to various end products (Fig. 5). The lipoxygenase pathway converts arachidonic acid to $12 \mathrm{~L}$-hydroperoxy-5,8,10,14-eicosatetraenoic acid (HPETE) that is then reduced to HETE, a 12hydroxy fatty acid. In contrast, the enzyme cyclooxygenase catalyzes the conversion of arachidonic acid to the endoperoxides $\mathrm{PGG}_{2}$ and $\mathrm{PGH}_{2}$. Thromboxane $\mathrm{A}_{2}\left(\mathrm{TXA}_{2}\right.$, $)$ the most potent platelet aggregator and blood vessel constrictor known, is formed enzymatically from either $\mathrm{PGG}_{2}$ or $\mathrm{PGH}_{2}$ in the presence of thromboxane synthetase. TXA $\mathrm{T}_{2}$ is very unstable and undergoes rapid hydrolysis to its inactive end product $\mathrm{TXB}_{2}$. The major alternative pathway for metabolism of the 20 carbon endoperoxides $\mathrm{PGG}_{2}$ and $\mathrm{PGH}_{2}$ in the platelet is to the 17 carbon hydroxy fatty acid, HHT and the 3 carbon fragment, malondialdehyde.

In contradistinction to these platelet products, arachidonic acid released from the endothelial lining of the vessel wall is converted to prostacyclin, also known as $\mathrm{PGI}_{2}$, in the presence of vascular cyclooxygenase. $\mathrm{PGI}_{2}$ inhibits platelet aggregation and causes vasodilatation. The balance between proaggregatory and prothrombotic platelet $\mathrm{TXA}_{2}$ and antithrombotic prostacyclin appears to affect normal hemostasis. Imbalances in their production may lead to a thrombotic tendency (14).

In our paired in vitro studies, we have found significant increases in the production by platelets of the potent proaggregatory substance $\mathrm{TXA}_{2}$ in the presence of L-homocystine and D,L-homocysteine. Because platelet HHT production is concomitantly elevated, these effects most likely occur as a result of increased activity of the platelet enzyme cyclooxygenase, rather than thromboxane synthetase (Fig. 1). At comparable concentrations, L-cystine, D,Lcysteine and $\mathrm{L}$-methionine had no significant effects in this system. No changes in antiaggregatory vascular $\mathrm{PGI}_{2}$ production were evident in our vascular incubation studies; thus, an imbalance in platelet-vascular prostaglandin synthesis favoring the production (a) HCE

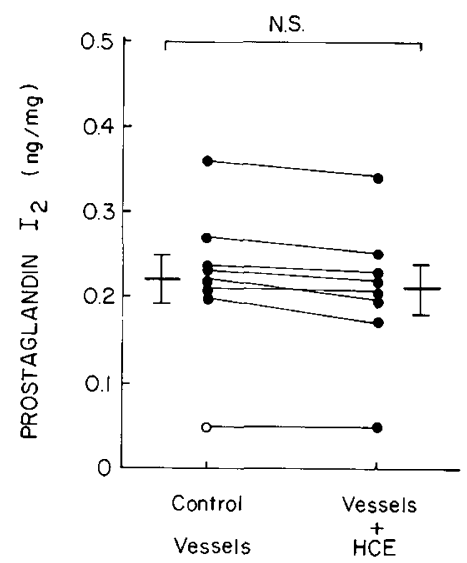

(b) HCI

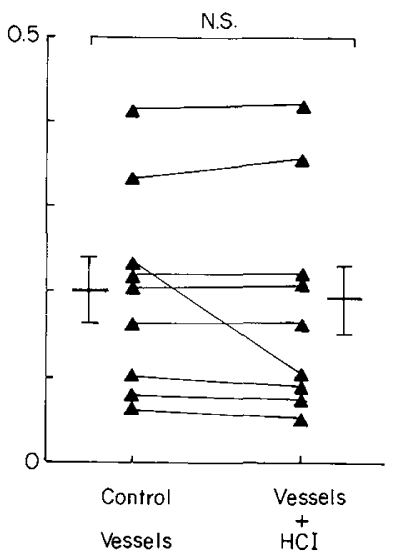

Fig. 4. Effect of D,L-homocysteine (HCE) and L-homocystine ( $\mathrm{HCI})$ (1 $\mathrm{mM})$ on vascular prostaglandin $\left(\mathrm{PGI}_{2}\right)$ formation.

of prothrombotic platelet $\mathrm{TXA}_{2}$ has been demonstrated in vitro in the presence of L-homocystine or D,L-homocysteine. Levels of 0.2 $\mathrm{mM}$ homocystine have been reported in patients with homocystinuria (15). Preliminary studies using in vitro concentrations of 0.2 $\mathrm{mM}$ gave equivocal results. Although an increase in both $\mathrm{TXB}_{2}$ and HHT were observed in some experiments, the results were not statistically significant. We chose a higher concentration of 1 $\mathrm{mM}$ for all test compounds studied because unlike the in vivo situation, our in vitro experiments were conducted using necessarily limited periods of exposure.

Patients with cystathionine- $\beta$-synthase deficiency have elevated methionine levels. There is clinical evidence that methionine accumulation is unlikely to be important in the genesis of the atherothrombotic lesions. Several patients with homocystinemia and low or normal methionine levels have had vascular lesions very similar to those found in patients with homocystinemia and hypermethioninemia $(2,9,10,11)$. As reported, we were not able to obtain an effect on prostaglandin production in vitro using methionine.

The atherothrombotic complications in cystathionine- $\beta$-synthase deficiency are not considered to be adequately explained either by a structural abnormality in collagen (4) or by abnormalities in the fluid phase of coagulation (8). Platelet function or survival studies in homocystinemic humans have not revealed consistent abnormalities $(1,3,7,12,17)$.

Platelet survival was decreased in L-homocysteine-infused primates compared to controls and these values returned toward normal upon treatment with the antiplatelet agent dipyridamole $(6,7)$. Patchy endothelial cell loss was seen in the animals chronically infused with homocysteine. These animals developed fibromusculoelastic lesions similar to those of atherosclerosis with the extent of lesions significantly decreased in the dipyridamoletreated group. The authors concluded that the underlying cause of the thrombotic and atherosclerotic tendency in homocystinemia 


\section{Transformation of Arachidonic Acid in Platelets}



Fig. 5. Metabolism of arachidonic acid through the cyclooxygenase and lipoxygenase pathways in the platelet.

may be sustained homocyst(e)ine-induced vascular endothelial injury, with the formation of platelet thrombi on altered nonendothelialized surfaces as a secondary event; local release of platelet constituents, including a platelet mitogenic factor, was thought to mediate intimal proliferation of smooth muscle cells and play an important role in the genesis of the characteristic vascular lesions.

Our finding of increased platelet proaggregatory thromboxane, induced by homocysteine or homocystine in the absence of a compensatory increase in antithrombotic vascular $\mathrm{PGI}_{2}$, appears compatible with the prothrombotic tendency seen in human homocystinemia. We recognize that these effects have been documented so far only under acute conditions in vitro and at concentrations of homocyst(e)ine in excess of the plasma concentrations chronically present in patients with cystathionine $\beta$-synthase deficiency (15). The possibility that a homocyst(e)ine induced proaggregatory increase in thromboxane production may contribute to the vascular occlusions in human homocystinemias is clearly not incompatible with the view that homocystinemia also induces vessel endothelial damage; both mechanisms, and/or others, could play a role in homocystinemic thromboembolism.

\section{REFERENCES AND NOTES}

1. Brett, E. M.: Homocystinuria with epilepsy. Proc. R. Soc. Med., 59: 484 (1966).

2. Baumgartner, E. R., Ulick. H., Maurer, R., Egli, N., and Steinman, B.: Congenital defect in intracellular cobalamin metabolism resulting in homocystinuria and methyl malonic aciduria. 1. Case report and histopathology. Helv. Paediatr. Acta, 34: 465 (1979)

3. Cline, J. W., Goyer, R. A., Lipton, J., and Mason, R. G.: Adult homocystinuria with ectopia lentis. South. Med. J., 64: 613 (1971).

4. Davis, J. W., Flournoy, L. D., and Philips, P. E.: Amino acids and collageninduced platelet aggregation: lack of effect of three amino acids that are elevated in homocystinuria. Am. J. Dis. Child., 129: 1020 (1975).

5. Hamberg, M., Svensson, J., and Samuelsson, S.: Thromboxanes: a new group of biologically active compounds derived from prostaglandin endoperoxides. Proc. Natl. Acad. Sci. USA, 72: 2994 (1975).

6. Harker, L. A., Ross, R., Slichter, S. J., and Scott, C. R.: Homocystine-induced arteriosclerosis: the role of endothelial cell injury and platelet response in its genesis. J. Clin. Invest., 58: 731 (1976).

7. Harker, L. A., Slichter, S. J., Scott, C. R., and Ross, R.: Homocystinemia: vascular injury and arterial thrombosis. N. Engl. J. Med., 291: 537 (1974).

8. Hilden, M., Brandt, N. J., Nilsson, I. M., and Schonheyder, F.: Investigations of coagulation and fibrinolysis in homocystinuria. Acta Med. Scand., 195: 533 (1974).

9. Kanwar, V. S., Manaligod, J. R., and Wong, P. W. K.: Morphologic studies in a patient with homocystinuria due to 5,10 -methylenetetrahydrofolate reductase deficiency. Pediatr. Res., 10: 598 (1976).

10. Levy, H. L.. Mudd, S. H., Schulman, J. D., Dreyfus, P. M., and Abeles. R. H.: A derangement in $B_{12}$ metabolism associated with homocystinemia, cystathioninemia, hypomethioninemia, and methylmalonic aciduria. Am. J. Med., 48: 390 (1970).

11. McCully, K. S.: Vascular pathology of homocysteinemia: implications for the pathogenesis of arteriosclerosis. Am. J. Pathol., 56: 111 (1969).

12. McDonald, L., Bray. C., Field. C., Love, F., and Davies, B.: Homocystinuria. thrombosis, and the blood-platelets. Lancet, 1: 745 (1964).

13. Moncada, S., Higgs. E. A., and Vane, J. R.: Human arterial and venous tissues generate prostacyclin (prostaglandin $\mathrm{X}$ ), a potent inhibitor of platelet aggregation. Lancet, 1 : 18 (1977).

14. Moncada, S. and Vane, J. R.: Arachidonic acid metabolites and the interactions between platelets and blood vessel walls. N. Engl. J. Med., 300: 1142 (1979).

15. Mudd, S. H. and Levy, H. L.: Disorders of transsulfuration. In: Stanbury, J. B., Wyngaarden, J. B. and Fredrickson, D. S. Eds.: The Metabolic Basis of Inherited Disease, p. 458, (4th edition, McGraw-Hill, New York, 1978).

16. Stuart, M. J., Gerrard, J. M., and White, J. G.: The influence of albumin and calcium on human platelet arachidonic acid metabolism. Blood, 55: 418 (1980).

17. Uhlemann, E. R., TenPas, J. H., Lucky, A. W., Schulman, J. D., Mudd, S. H., and Schulman, N. R.: Platelet survival and morphology in homocystinuria due to cystathionine synthase deficiency. N. Engl. J. Med., 295: 1283 (1976).

18. Requests for reprints should be addressed to: Dr. Janet E. Graeber, NIH, Bldg. 10, Rm 8C-429. Bethesda. MD 20205.

19. This research was supported in part by a grant from the National Foundation March of Dimes to M.J.S.

20. Received for publication August 19, 1981.

21. Accepted for publication February 5, 1982. 